\section{REDIMAT}

Journal of Research in Mathematics Education
Hipatia Press

www.hipatiapress.com

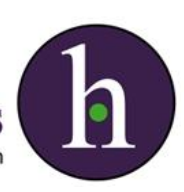

Instructions for authors, subscriptions and further details:

http://redimat.hipatiapress.com

\title{
Teaching Fractions through Situations: A Fundamental Experiment.
}

Claire Margolinas ${ }^{1}$

1) Laboratoire ACTé, Clermont-Université, France.

Date of publication: June $24^{\text {th }}, 2014$

Edition period: June 2014-October 2014

To cite this article: García, F.J. (2014). Teaching Fractions through Situations: A Fundamental Experiment. REDIMAT, 3(2), 186-188. doi: 10.4471/redimat.2013.49

To link this article: http://dx.doi.org/10.4471/redimat.2014.49

PLEASE SCROLL DOWN FOR ARTICLE

The terms and conditions of use are related to the Open Journal System and to Creative Commons Attribution License (CC-BY). 
REDIMAT, Vol. 3 No. 2 June $24^{\text {th }} 2014$ pp. 186-188

\section{Review}

Brousseau, G., Brousseau, N., \& Warfield, G. (2014). Teaching Fractions through Situations: A Fundamental Experiment. Dordrecht Heidelberg NewYork London: Springer.

$\neg$ this book presents the 'adventures' that have been lived by researchers, students and teachers at the Center for Observation L and Research in Mathematics Education (Centre pour l'Observation et la Recherche sur l'Enseignement des Mathématiques, COREM, 1973-1999, Talence, France).

The point of departure is a research question, which has been the central focus of the development of the Theory of Didactical Situations in Mathematics (Brousseau, 1997): is it possible for taught mathematics at school to be similar to the mathematical process practiced and produced by mathematicians?

Would it be possible to produce and discuss such a process?

Would the students - all the students- be able to engage in it?

Could the result of the process be, for each of the students, a stage

of knowledge at least equal to that obtained by current, standard methods? (p. 129)

Fractions (rational numbers) were chosen in this research because their teaching was "both significant and challenging" (p.5), at primary school (end of primary school: 9 to 11 year-old students). Thus the project focused on understanding better the phenomena at stake during the teaching and learning of this very significant and challenging piece of knowledge, and not only to design some 'ideal' way of teaching fractions.

However, the design by itself and the theoretical development of the Theory of Didactical Situations cannot be separated, and this book provides, for the first time since the research itself has been initiated during the 70 's, an integrated understanding of both aspects. 
If you are interested in the design and in the mathematical and didactical original choices to teach fraction as rational numbers, from the starting point of rational numbers as measurement to the ending point of linear mapping, you will be enlighten by 'The Adventure as Experienced by the Students' (pp. 9-124) where the whole process is described in a very detailed and precise way. You will get a glimpse of the procedures of the students in the situations that have been designed and implemented during the long period of COREM existence.

If you are more interested in the modeling of teaching and teacher's role in this process, you may start with 'The Adventure as Experienced by the Teachers' (pp. 127-161) where the links with the crucial concepts of the theory are developed. You will find in particular the important distinction between 'connaissance' and 'savoir', which is difficult to find in English the appropriate words. In Latin languages, there are two words derived from the Latin sapere and conoscere (in French savoir and connaissance) that correspond to only one word in English: 'knowledge'. These words have been used by Brousseau to highlight two different aspects of knowledge. On the one hand, knowledge is useful in situation, which is the connaissance aspect. On the other hand, mathematics has been accumulated, formulated, formalized, written, becoming part of our culture, which is the savoir aspect. The main question guiding Brousseau's adventures may be reformulated using this vocabulary: is it possible to teach mathematics in a way that assures the acquisition of both: knowledge in situation (connaissance) and social knowledge (savoir)? A better understanding of the teaching itself and teacher's role in relation to the savoir and connaissance dialectic is one of the most important outcomes of this book.

If you are most interested in the methodological challenge of COREM: a whole school for the observation of mathematics teaching for 25 years, and the mutual relations between the theory development itself and the substantial resources which were designed, developed, collected, analyzed, etc. during this period, you may start by 'The Adventure as Experienced by the Researchers' (pp. 165-200).

Because this book is not a linear one, it can be read from different points of view. You will experience an adventure yourself, which will certainly have an impact on all the aspects: the mathematical approach to fractions and 
188 Margolinas - Teaching Fractions through Situations

their learning, the theoretical development of very important concepts and the methodological requirement for research in Mathematics Education.

\section{References}

Brousseau, G. (1997). Theory of Didactical Situations in Mathematics.

Dordrecht: Kluwer Academic Publishers.

Claire Margolinas, Laboratoire ACTé, Clermont-Université claire.margolinas@univ-bpclermont.fr 